\title{
Prospective Observational Study of Predictors of Re-Intubation Following Extubation in the Surgical ICU
}

\author{
Annop Piriyapatsom MD, Elizabeth C Williams MD, Karen Waak DPT, Karim S Ladha MD, \\ Matthias Eikermann MD, and Ulrich H Schmidt MD PhD MBA
}

\begin{abstract}
BACKGROUND: Re-intubation is associated with high morbidity and mortality. There is limited information regarding the risk factors that predispose patients admitted to the surgical ICU to re-intubation. We hypothesized that preoperative comorbidities, acquired muscular weakness, and renal dysfunction would be predictors of re-intubation in the surgical ICU population. METHODS: This was a prospective observational study in 2 surgical ICUs of a large tertiary hospital. All patients who were extubated during their surgical ICU stay were included. Demographic and clinical data were collected before and after extubation. The primary outcome was re-intubation within $72 \mathrm{~h}$. Using multivariate logistic regression analysis, independent risk factors of re-intubation were determined, and a prediction score was developed. RESULTS: Between December 1, 2012, and January 31, 2014, we included 764 consecutive subjects. Of these, 65 subjects $(8.5 \%)$ required re-intubation. Independent risk factors of re-intubation were blood urea nitrogen level of $>8.2$ mmol/L (odds ratio [OR] 3.66, 95\% CI 1.97-6.80), hemoglobin level of $<75 \mathrm{~g} / \mathrm{L}$ (OR 2.10, 95\% CI 1.23-3.61), and muscle strength of $\leq 3$ (OR 2.03, 95\% CI 1.16-3.55). The presence of all 3 risk factors was associated with an estimated probability for re-intubation of $26.8 \%$. CONCLUSIONS: In noncardiac surgery, surgical ICU subjects, elevated blood urea nitrogen level, low hemoglobin level, and muscle weakness were identified as independent risk factors for re-intubation. The presence of these risk factors can potentially aid clinicians in making informed decisions regarding optimal airway management in patients considered for an extubation attempt. (ClinicalTrials.gov registration NCT01967056.) Key words: critically ill; prediction score; re-intubation; risk factors; surgical. [Respir Care 2016;61(3):306-315. ( 2016 Daedalus Enterprises]
\end{abstract}

\section{Introduction}

Over the last decade, a systematic approach for liberation from mechanical ventilation and tracheal extubation,

\footnotetext{
Dr Piriyapatsom is affiliated with the Department of Anesthesiology, Siriraj Hospital, Mahidol University, Bangkok, Thailand. Drs Williams, Ladha, and Eikermann are affiliated with the Department of Anesthesia, Critical Care, and Pain Medicine, and Dr Waak is affiliated with the Department of Physical and Occupational Therapy, Massachusetts General Hospital, Harvard University, Boston, Massachusetts. Dr Schmidt is affiliated with the Department of Anesthesiology, University of California San Diego, San Diego, California.

Dr Williams presented some parts of this work as a poster presentation at the 43rd Critical Care Congress of the Society of Critical Care Medicine, held January 10, 2014, in San Francisco, California.
}

The authors have disclosed no conflicts of interest. including spontaneous awakening and breathing trials, has been recommended and has resulted in decreased duration of mechanical ventilation. ${ }^{1-4}$ The incidence of extubation failure reported in the literature varies from 6 to $40 \% .^{5-19}$ Re-intubation in nonsurgical critically ill patients is associated with increased mortality $5,9,13,14,16-18,20$ and morbidity, including prolonged mechanical ventilation support, $, 9,14$ ventilator-associated pneumonia, ${ }^{13,14,21}$ organ failure, ${ }^{13,14}$ and prolonged length of stay (LOS). $5,9,14-17$ The most common reason for re-intubation reported is respiratory distress due to either primary respiratory failure or secondary causes, such as congestive heart failure, hemodynamic in-

Correspondence: Ulrich H Schmidt MD PhD MBA, 200 West Arbor Drive \#8770 San Diego, CA 92103. E-mail: uschmidt@ucsd.edu.

DOI: $10.4187 /$ respcare.04269 
stability, airway obstruction from postextubation stridor or airway edema, inability to clear airway secretions, or altered mental status. 6,7,11,13-17,19,20,22

In critically ill patients, some predisposing factors for re-intubation have been proposed in the literature. Acquired muscle weakness is associated with aspiration, ${ }^{23}$ prolonged weaning from mechanical ventilation, and weaning failure..$^{22,24-26}$ The high mortality seen in critically ill patients with renal failure has been attributed to the need for mechanical ventilation, ${ }^{27}$ and renal failure per se has been identified as an independent risk factor for prolonged mechanical ventilation and weaning failure. ${ }^{27-30}$ In surgical patients, the etiologies leading to tracheal intubation and mechanical ventilation might, in some aspect, differ from those of medical patients. We recently developed and validated the score for prediction of postoperative respiratory complications. ${ }^{31}$ This score predicts the risk of extubation failure following surgery based on the patient's comorbidities and the acuity of disease leading to surgery, including the American Society of Anesthesiologists physical status, emergency surgery, high-risk surgical service, history of congestive heart failure and chronic pulmonary disease. The score ranges from 0 to 11, with a higher score predicting a higher likelihood for postoperative re-intubation. Nevertheless, the predictors for re-intubation in the critically ill surgical population have not been studied in detail. We therefore aimed to determine the risk factors for re-intubation in the surgical ICU population. We hypothesized that preoperative comorbidities, acquired muscular weakness, and renal dysfunction would be predictors of re-intubation in the surgical ICU population. Additionally, we sought to develop a score predicting re-intubation in this patient population.

\section{Methods}

\section{Setting}

This prospective observational study was approved by the institutional review board of Massachusetts General Hospital (Boston, Massachusetts). The study was conducted between December 1, 2012, and January 31, 2014, in 2 surgical ICUs at Massachusetts General Hospital, which is a university-affiliated, tertiary care referral and level-1 trauma center.

\section{Patient Population}

All adult patients admitted to these 2 surgical ICUs were eligible for enrollment if they were intubated and required mechanical ventilation during their surgical ICU stay. The patient care plan as well as the decision to liberate from mechanical ventilation and to extubate were directed by the surgical ICU team. Per standardized pro-

\section{QUICK LOOK}

\section{Current knowledge}

The incidence of extubation failure reported in the literature varies from 6 to $40 \%$. Re-intubation in nonsurgical critically ill patients is associated with increased mortality and morbidity. In medical patients, the most common reasons for re-intubation are respiratory distress due to either primary respiratory failure or secondary causes such as congestive heart failure, hemodynamic instability, airway obstruction, inability to clear airway secretions, or altered mental status.

\section{What this paper contributes to our knowledge}

In a surgical ICU population, $8.5 \%$ of subjects required re-intubation. Independent risk factors of reintubation were elevated blood urea nitrogen level, low hemoglobin, and decreased muscle strength. These parameters have been included in a prediction score for re-intubation.

tocol, ${ }^{3}$ spontaneous awakening and spontaneous breathing trials were performed in each patient. The surgical ICU team then decided whether to extubate the patient. Once the patients were extubated, they were included in the study and were followed for up to $30 \mathrm{~d}$ or until discharge from the hospital. Patients with terminal extubation (extubation with comfort measure orders in place), those who died without an extubation attempt, and those with tracheostomy placement without an extubation attempt were excluded from the study.

\section{Data Collection}

After a review of the literature, we held multidisciplinary focus groups with surgical and medical intensivists, respiratory therapists, physical therapists, and surgical ICU nurses to pre-identify potential predictors for respiratory failure after extubation, which included demographics, underlying and acute illness, and subjects' clinical profiles assessed during the $24 \mathrm{~h}$ before extubation.

Demographic data and acute illness included age, gender, body mass index (BMI), past medical history, type of surgical ICU admission (whether following elective or emergency surgery or no surgery), APACHE II (Acute Physiology and Chronic Health Evaluation) score, laboratory values at surgical ICU admission, the development of acute kidney injury defined as the RIFLE (risk, injury, failure, loss, and end-stage kidney) classification of 1 or higher, ${ }^{32}$ and duration of mechanical ventilation. The score for prediction of postoperative respiratory complications, ${ }^{31}$ 
the American Society of Anesthesiologists physical status, and sites of surgery were additionally recorded in subjects admitted to the surgical ICU following surgery. For nonpostoperative subjects, reasons for intubation were determined and recorded.

Subjects' clinical profiles obtained during the $24 \mathrm{~h}$ before extubation included the mechanical ventilation settings before the spontaneous breathing trial, oxygen saturation, $\mathrm{P}_{\mathrm{aO}} / \mathrm{F}_{\mathrm{IO}_{2}}$, results of the spontaneous breathing trial and cuff leak test performed by the bedside respiratory therapists, number of tracheal suctions needed, muscle strength before extubation, fluid balance, and medications administered. In our surgical ICUs, the muscle strength of the extremities was routinely assessed by the bedside nurses and scored ranging from 0 to 4 as no visible movement of limb, inability to overcome gravity but ability to move in the plane of the supported limb, ability to overcome gravity but not resistance, ability to overcome both gravity and resistance, and normal motor power, respectively. The average muscle strength over 4 extremities was recorded. This scale was tested for inter-rater agreement with the Medical Research Council (MRC) sum score ${ }^{33}$ in 50 randomly selected subjects by a well-trained physical therapist (KW) who was blinded from the study. The MRC sum score has been widely used for assessing muscle strength. In brief, the score is the sum of the muscle strength grading scale comprehensively tested on 6 muscle groups on both limbs, including deltoid, biceps, wrist extensor, iliopsoas, quadriceps femoris, and tibialis anterior. The scale ranges from 0 (paralysis) to 5 (normal strength); therefore, the sum score ranges from 0 to $60 . .^{33}$ The medications recorded included neuromuscular blocking agents, neostigmine, opioids, hypnotics, steroids, and vasopressors.

\section{Outcomes}

As per the protocol of the surgical ICU, subjects were started on face mask oxygen after extubation and were then weaned to nasal cannula if the oxygenation remained above the threshold prescribed by the clinicians. The primary end point for this study was re-intubation within $72 \mathrm{~h}$ after extubation. Subjects who required intubation within this time frame for a surgical procedure were not considered as receiving re-intubation. Reasons for re-intubation were also determined and recorded. The secondary end points were LOS in the surgical ICU and in the hospital as well as in-hospital mortality. We also recorded respiratory status following extubation, including $\mathrm{F}_{\mathrm{IO}_{2}}$ requirement, $\mathrm{P}_{\mathrm{aO}_{2}} / \mathrm{F}_{\mathrm{IO}_{2}}$, and oxygen saturation; the use of noninvasive ventilation (NIV); either bi-level positive airway pressure or CPAP for either prevention or treatment of extubation failure; and tracheostomy placement. At our hospital, there were $24 / 7$ in-house surgical ICU physicians. The strategy for management of failing subjects was based on the pro- tocol of our surgical ICU. For subjects with hypercarbic respiratory failure, NIV was the first line treatment. If no significant improvement was observed, subjects were endotracheally intubated. Subjects with hypoxic respiratory failure were directly re-intubated. Nevertheless, the final decision regarding initiation of NIV as well as the timing of tracheostomy placement was made by the ICU attending.

\section{Statistical Analysis}

Subjects were categorized into 2 groups based on whether they required re-intubation or not. Categorical variables were presented as a number with proportion and were compared between groups using the Pearson chi-square or the Fisher exact test when appropriate. Continuous variables were presented as median with interquartile range (IQR) and were compared between groups using the MannWhitney $\mathrm{U}$ test. The inter-rater agreement between the muscle strength scale assessed by the bedside nurse and the MRC sum score evaluated by the physical therapist was tested using the Cohen kappa coefficient. To determine the independent risk factors of re-intubation, the predefined variables, including age, sex, chronic pulmonary and cardiovascular diseases, severity of illness, and duration on mechanical ventilation, as well as significant variables from the univariate analysis were further analyzed using multivariate logistic regression analysis in a backward stepwise fashion. The final model included only variables with a $P$ value of $<.05$. If continuous variables remained in the model, optimal cut-off points based on the receiver operating characteristic curves were specified using the Youden index. A point value was assigned to each variable proportional to the estimates from the multivariate logistic regression model. For this, the $\beta$ estimate of each predictor was divided by the smallest estimate. These results were rounded to the nearest whole number to define the score point values. The predictive value of the score for re-intubation was assessed using analysis of the area under the receiver operating characteristic curve. The probabilities for re-intubation depending on the score values were also determined. All statistical tests were performed using SAS 9.2 (SAS Institute, Cary, NC). A 2-sided $P$ value of $<.05$ was considered statistically significant.

\section{Results}

\section{Study Cohort and Patients' Characteristics}

During the study period, 917 consecutive patients were eligible for enrollment (Fig. 1). Of these, 153 patients were excluded (70 patients underwent tracheostomy placement without extubation attempt, and 83 patients died without an extubation attempt), leaving 764 subjects included in 


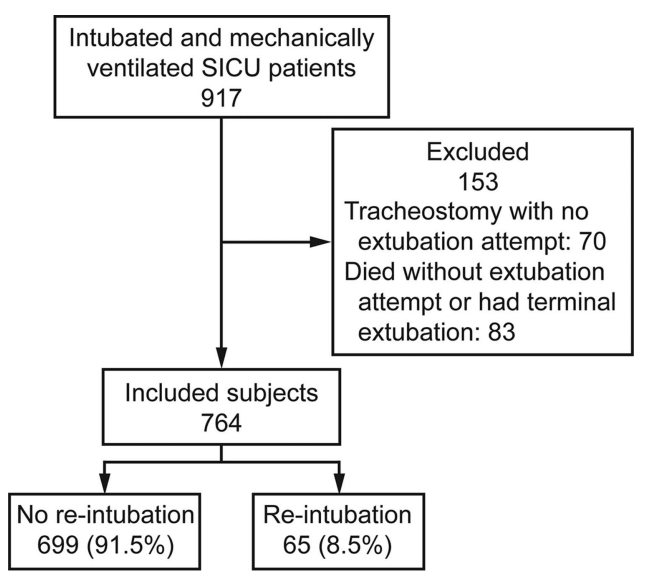

Fig. 1. Flow chart. SICU = surgical intensive care unit.

the study. Overall, 65 of 764 subjects $(8.5 \%)$ required re-intubation.

Table 1 shows the demographic data and acute illness of subjects with and without re-intubation. There was no significant difference in the baseline demographic data between groups. There was a higher proportion of non-postoperative surgical ICU admission (32.3\% vs $21.5 \%$, $P=.045)$ but a lower proportion of surgical ICU admission after elective surgery $(32.3 \%$ vs $48.8 \%, P=.01)$ in the re-intubation group compared with that in the no reintubation group. Subjects requiring re-intubation had higher APACHE II scores (median 17 [IQR 13-22] vs 15 [11-19], $P=.003)$, lower hemoglobin level (72 [6981] g/L vs 81 [72-96] g/L, $P<.001)$, lower serum albu$\min (30$ [24-37] g/L vs 33 [27-40] g/L, $P=.03)$, higher blood urea nitrogen level (BUN) (12.5 [8.2-22.1] mmol/L vs 7.1 [4.6-13.6] $\mathrm{mmol} / \mathrm{L}, P<.001)$, and higher serum creatinine (129.1 [79.6-229.8] $\mu \mathrm{mol} / \mathrm{L}$ vs 93.7 [66.3155.6] $\mu \mathrm{mol} / \mathrm{L}, P=.002)$ compared with those without re-intubation. In addition, re-intubated subjects more frequently carried the diagnosis of acute kidney injury (53.8\% vs $34.6 \%, P=.002)$ and had longer duration of mechanical ventilation (median 73 [IQR $30-146]$ h vs 31 [1868] h, $P<.001)$ compared with those who were not reintubated.

Among 593 subjects admitted to the surgical ICU after either elective or emergency surgery, there were 44 subjects $(7.4 \%)$ who required re-intubation (Table 1). When compared with subjects without re-intubation, those who required re-intubation had more frequent vascular site of surgery $(29.5 \%$ vs $15.8 \%, P=.02)$, more frequent American Society of Anesthesiologists physical status of $\geq 3$ (92.3\% vs $79.1 \%, P=.01)$, and a higher score for prediction of postoperative respiratory complications (median 7 [IQR 5-8] vs 5 [3-7], $P<.001)$. Meanwhile, there were $21(12.3 \%)$ of 171 non-postoperative subjects who required re-intubation (Table 1). Within this subgroup, re-intubated subjects had a higher frequency of respiratory failure as a reason for intubation when compared with those without re-intubation $(57.1 \%$ vs $32.0 \%, P=.03)$.

\section{Subjects' Clinical Profiles Assessed During 24 h Before Extubation}

Table 2 shows the subjects' profiles assessed during the $24 \mathrm{~h}$ before extubation. There was no difference in mechanical ventilation settings before the spontaneous breathing trials between groups. When compared with subjects without re-intubation, re-intubated subjects had lower oxygen saturation before extubation (median 98 [IQR 9799]\% vs $99[98-100] \%, P=.006)$. However, there was no significant difference in $\mathrm{P}_{\mathrm{aO}} / \mathrm{F}_{\mathrm{IO}_{2}}$ between groups. There was also no significant difference in the rate of failed spontaneous breathing trial and negative cuff leak test between groups. Re-intubated subjects had lower muscle strength when compared with those without re-intubation (median 3 [IQR 2-3] vs 3 [3-4], $P<.001$ ). The average muscle strength assessed by the bedside nurses had a $46.0 \%$ inter-rater agreement and a 0.25 Cohen kappa coefficient with the MRC sum score (validated in 50 randomly selected subjects). Regarding the medication administered during $24 \mathrm{~h}$ before extubation, re-intubated subjects more frequently received sedative medications (haloperidol, $38.5 \%$ vs $16.9 \%, P<.001$; dexmedetomidine, $30.8 \%$ vs $14.9 \%, P=.001$; quetiapine, $12.3 \%$ vs $4.7 \%, P=.18$ ) but less frequently received neuromuscular blocking agents ( $29.2 \%$ vs $41.8 \%, P=.049)$. However, there was no significant difference in the frequency of reversal with neostigmine between groups ( $4.6 \%$ in re-intubation group vs $1.1 \%$ in no re-intubation group, $P=.059$ ).

\section{Predictors for Re-Intubation and Prediction Scores}

Using a stepwise regression model, 3 variables were identified as independent predictors for re-intubation, and the optimal cutoff points were specified for these predictors. Independent risk factors of re-intubation were BUN of $>8.2 \mathrm{mmol} / \mathrm{L}$ (OR 3.66, 95\% CI 1.97-6.80), hemoglobin level of $<75 \mathrm{~g} / \mathrm{L}$ (OR 2.10, 95\% CI 1.23-3.61), and muscle strength of $\leq 3$ (OR 2.03, 95\% CI 1.16-3.55) (Table 3). A point value was then assigned to each variable proportional to the estimates from the logistic regression model: $\mathrm{BUN}$ of $>8.2 \mathrm{mmol} / \mathrm{L}, 2$ points; hemoglobin level of $<75 \mathrm{~g} / \mathrm{L}, 1$ point; and muscle strength of $\leq 3,1$ point (Table 3). The summed point values of the developed score ranged from 0 to 4 . The score led to an area under the receiver operating characteristic curve of 0.73 (Fig. 2), and a value of $0,1,2,3$, and 4 was associated with an estimated probability for re-intubation of 2.3, 4.5, 8.5, 15.6, and $26.8 \%$, respectively (Fig. 3). 


\section{Predictors of Re-Intubation In the Surgical ICU}

Table 1. Demographics and Underlying and Acute Illness of Subjects With and Without Re-Intubation

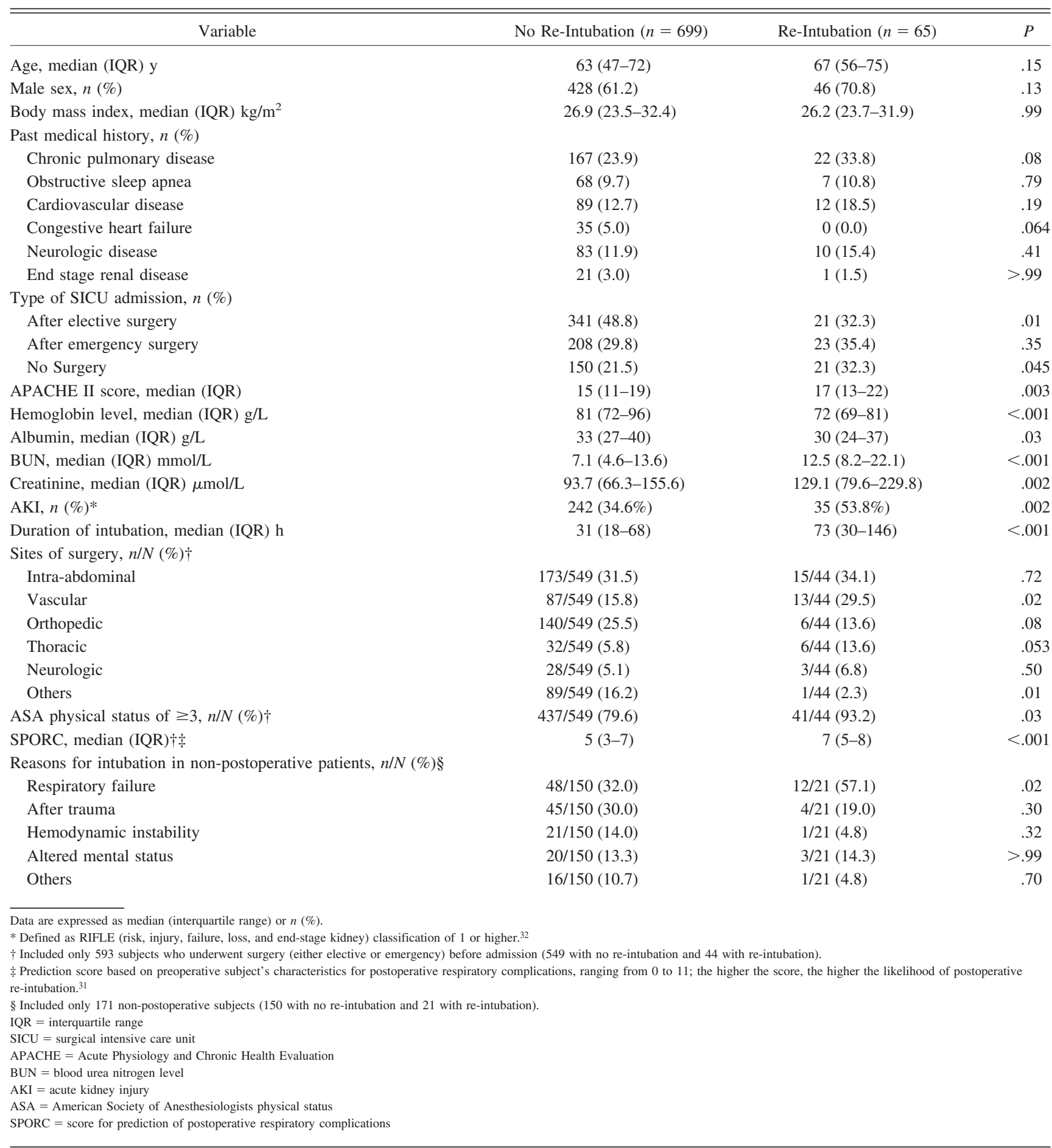

\section{Subjects' Status Following 72-h Postextubation and Clinical Outcomes}

While requiring higher $\mathrm{F}_{\mathrm{IO}_{2}}$ after extubation (median 0.36 [IQR 0.24-0.42] vs 0.21 [0.21-0.24], $P<.001$ ), re-intubated subjects had lower $\mathrm{P}_{\mathrm{aO}_{2}} / \mathrm{F}_{\mathrm{IO}_{2}}$ compared with those without re-intubation (169 [109-228[ mm Hg vs 279 [203-371] mm Hg, $P<.001)$. These subjects also had more frequent oxygen desaturation after extubation $(72.3 \%$ vs $28.5 \%, P<.001$ ), and NIV was more frequently applied $(40.0 \%$ vs $9.2 \%, P<.001)$. When compared with subjects without re-intubation, those with re-intubation had 


\section{Predictors of Re-Intubation IN the Surgical ICU}

Table 2. Clinical Profiles Assessed During 24 h Prior to Extubation of Subjects With and Without Re-Intubation

\begin{tabular}{|c|c|c|c|}
\hline Variable & No Re-Intubation $(n=699)$ & Re-Intubation $(n=65)$ & $P$ \\
\hline \multicolumn{4}{|l|}{ Ventilator setting prior to SBT } \\
\hline \multicolumn{4}{|l|}{ Mode, $n(\%)$} \\
\hline PSV & $583(83.4)$ & $60(92.3)$ & .11 \\
\hline CPAP & $30(4.3)$ & $2(3.1)$ & \\
\hline PC-CMV & $57(8.2)$ & $0(0.0)$ & \\
\hline VC-CMV & $29(4.1)$ & $3(4.6)$ & \\
\hline PEEP, median (IQR) $\mathrm{cm} \mathrm{H}_{2} \mathrm{O}$ & $5(5-5)$ & $5(5-5)$ & .07 \\
\hline $\mathrm{F}_{\mathrm{IO}_{2}}$, median $(\mathrm{IQR})$ & $.40(0.30-0.40)$ & $.40(0.30-0.40)$ & .62 \\
\hline $\mathrm{S}_{\mathrm{pO}_{2}}$, median (IQR) $\%$ & $99(98-100)$ & $98(97-99)$ & .006 \\
\hline $\mathrm{P}_{\mathrm{aO}_{2}} / \mathrm{F}_{\mathrm{IO}_{2}}$, median (IQR) $\mathrm{mm} \mathrm{Hg}$ & $320(255-400)$ & $308(238-363)$ & .10 \\
\hline Failed SBT, $n(\%)$ & $7(1.0)$ & $1(1.5)$ & .84 \\
\hline Cuff leak test: not present, $n(\%)$ & $8(1.1)$ & $0(0.0)$ & .66 \\
\hline No. of tracheal suctions needed, median (IQR) & $4(2-7)$ & $5(3-7)$ & .056 \\
\hline Muscle strength, median (IQR)* & $3(3-4)$ & $3(2-3)$ & $<.001$ \\
\hline Fluid balance, median (IQR) mL & $756(-470$ to 2,415$)$ & $505(-750$ to 1,592$)$ & .17 \\
\hline \multicolumn{4}{|l|}{ Medication } \\
\hline NMBAs, $n(\%)$ & $292(41.8)$ & $19(29.2)$ & .049 \\
\hline Neostigmine, $n(\%)$ & $8(1.1)$ & $3(4.6)$ & .059 \\
\hline Opioids, $n(\%)$ & $622(89.0)$ & $57(87.7)$ & .75 \\
\hline Dose (morphine equivalent), median (IQR) mg & $25.3(12.0-56.0)$ & $28.9(8.6-81.0)$ & .61 \\
\hline Propofol, $n(\%)$ & $610(87.3)$ & $58(89.2)$ & .65 \\
\hline Dose, median (IQR) mg & $1,789(847-3,109)$ & $1,935(974-3,218)$ & .70 \\
\hline Haloperidol, $n(\%)$ & $118(16.9)$ & $25(38.5)$ & $<.001$ \\
\hline Dose, median (IQR) mg & $5(5-15)$ & $5(5-14)$ & .92 \\
\hline Dexmetomidine, $n(\%)$ & $104(14.9)$ & $20(30.8)$ & .001 \\
\hline Dose, median (IQR) $\mu \mathrm{g} / \mathrm{kg} / \mathrm{h}$ & $0.50(0.30-0.80)$ & $0.70(0.40-1.35)$ & .07 \\
\hline Quetiapine, $n(\%)$ & $33(4.7)$ & $8(12.3)$ & .02 \\
\hline Dose, median (IQR) mg & $50(25-100)$ & $75(25-181)$ & .54 \\
\hline Steroids, $n(\%)$ & $170(24.3)$ & $14(21.5)$ & .62 \\
\hline Vasopressors, $n(\%)$ & $324(46.4)$ & $34(52.3)$ & .36 \\
\hline
\end{tabular}

Data are expressed as median (interquartile range) or $n(\%)$.

* Average muscle strength over 4 extremities assessed by the bedside nurses and scored ranging from 0 to 4 as no visible movement of limb, inability to overcome gravity but ability to move in the plane of the supported limb, ability to overcome gravity but not resistance, ability to overcome both gravity and resistance, and normal motor power, respectively.

SBT $=$ spontaneous breathing trial

$\mathrm{PSV}=$ pressure support ventilation

PC-CMV = pressure control continuous mandatory ventilation

$\mathrm{VC}-\mathrm{CMV}=$ volume control continuous mandatory ventilation

$\mathrm{IQR}=$ interquartile range

NMBAs = neuromuscular blocking agents

a higher rate of tracheostomy placement $(60.0 \%$ vs $2.7 \%$, $P<.001$ ), longer LOS in the surgical ICU (median 16 [12-26] d vs 6 [4-9] d, $P<.001)$ and in the hospital (31 [22-44] d vs 16 [9-27] d, $P<.001)$, and higher hospital mortality $(20.0 \%$ vs $5.7 \%, P<.001)$.

There were a total of $90(11.8 \%)$ subjects who required NIV after extubation. Of these 90 subjects, 26 (28.9\%) required re-intubation. Subjects who required re-intubation following an NIV attempt, when compared with those who did not require re-intubation, had a higher rate of tracheostomy $(61.5 \%$ vs $4.7 \%, P<.001)$, longer surgical ICU LOS (median 18 [IQR 11-24] d vs 8 [5-15] d, $P<.001)$, longer hospital LOS (30 [23-45] d vs 18, 11-37 d, $P=.002$ ), and a trend toward higher mortality
(26.9\% vs $14.1 \%, P=.22$ ). Among 65 re-intubated subjects, the median time (IRQ) to re-intubation was 21.3 (7.3-43.0) $\mathrm{h}$ after extubation. Of these, 21 (32.3\%) and 36 $(55.4 \%)$ were re-intubated within 12 and $24 \mathrm{~h}$, respectively. The reasons for re-intubation were classified as respiratory distress $(70.8 \%)$, secretion-related problems $(18.5 \%)$, and airway-related problems (10.8\%).

\section{Discussion}

The most important results in our prospective study were that high BUN, low hemoglobin level, and muscle weakness were identified as independent predictors for re-intubation in a large population of noncardiac surgical ICU 
Table 3. Variables Independently Associated With Re-Intubation and Prediction Scores

\begin{tabular}{|c|c|c|c|c|}
\hline \multirow{2}{*}{ Variable } & \multicolumn{3}{|c|}{ Logistic Regression Analysis } & \multirow{2}{*}{$\begin{array}{l}\text { Assigned } \\
\text { Points }\end{array}$} \\
\hline & Odds Ratio & $95 \% \mathrm{CI}$ & $P$ & \\
\hline $\mathrm{BUN},>8.2 \mathrm{mmol} / \mathrm{L}$ & 3.66 & $1.97-6.80$ & $<.001$ & 2 \\
\hline $\begin{array}{l}\text { Hemoglobin level, } \\
\quad<75 \text { g/L }\end{array}$ & 2.10 & $1.23-3.61$ & .007 & 1 \\
\hline Muscle strength, $\leq 3 *$ & 2.03 & $1.16-3.55$ & .01 & 1 \\
\hline
\end{tabular}

* Average muscle strength over 4 extremities assessed by bedside nurses and scored ranging from 0 to 4 as no visible movement of limb, inability to overcome gravity but ability to move in the plane of the supported limb, ability to overcome gravity but not resistance, ability to overcome both gravity and resistance, and normal motor power, respectively. BUN $=$ blood urea nitrogen level

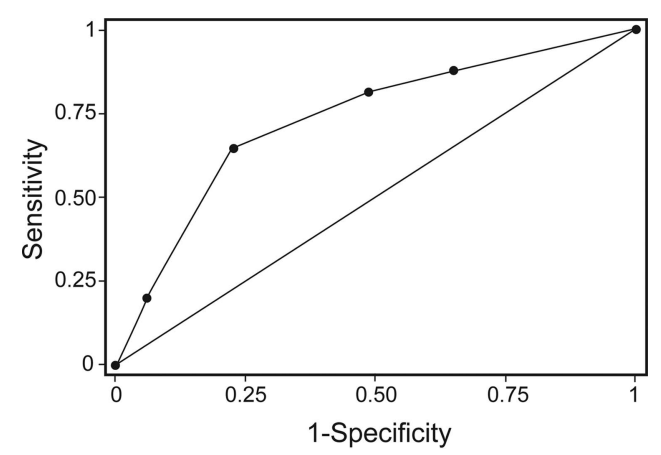

Fig. 2. Receiver operating characteristic curve of the developed prediction score for re-intubation. Area under the curve $=0.73$.

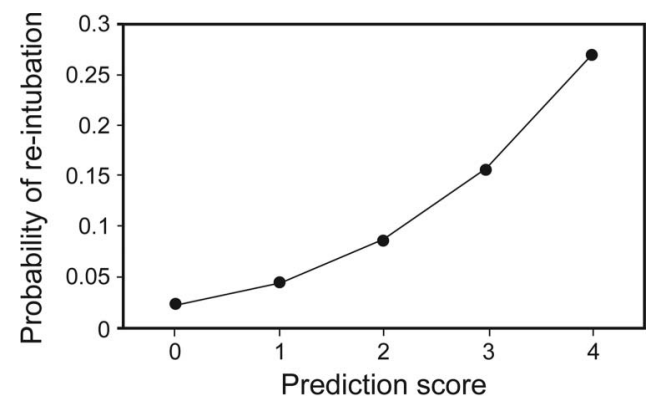

Fig. 3. Estimated probabilities for re-intubation according to different prediction scores.

subjects. The presence of all 3 parameters was associated with a $26.8 \%$ probability of re-intubation, a 10 -fold higher probability compared with those without any predictor. In studies in medical, neurological, or mixed ICUs, many variables have been identified as risk factors for extubation failure and re-intubation, such as age and underlying diseases, ${ }^{14}$ severity of acute illness, ${ }^{11,12,19}$ impairment of oxygenation, ${ }^{6,18}$ the amount of secretions, $, 7,8,10,19$ cough strength, ${ }^{7,8,12}$ or mental status. $6,8,10,15$ These variables were included in our model. However, they were not independent predictors of re-intubation in our study. This might be explained, in part, by the difference in patient population. We included only mechanically ventilated subjects in the surgical ICUs, whereas most other studies concentrated either on medical ${ }^{7,8,14,18}$ or neurological ICU subjects. ${ }^{6,11}$

In our study, increased BUN level was identified as an independent predictor for re-intubation. Elevation of BUN levels is associated with increased long-term mortality. ${ }^{34,35}$ In most critically ill patients, such abnormal values are often from renal dysfunction, mainly acute kidney injury. Both acute kidney injury and elevated BUN have been identified as independent risk factors for prolonged mechanical ventilation and weaning failure..$^{27-30}$ The results of these earlier studies support our findings that increased BUN was an independent risk factor for re-intubation.

More than one-third of critically ill subjects develop anemia during their hospitalization, and this has been considered as a marker of severity of illness. ${ }^{36-38}$ In addition, hemoglobin levels of $<80 \mathrm{~g} / \mathrm{L}$ have been reported as a risk factor for weaning failure and re-intubation. ${ }^{7,39}$ However, current practice guidelines on liberation from mechanical ventilation have not recommended the optimal hemoglobin levels for weaning and extubation. ${ }^{3,4}$ Nowadays, there is growing evidence demonstrating that a restrictive transfusion strategy with a lower hemoglobin transfusion trigger is not associated with increased morbidity and mortality in adult subjects or that it is even associated with better outcome in some subjects. ${ }^{40-43}$ Nevertheless, we cannot conclude from our study that a hemoglobin level of $<75 \mathrm{~g} / \mathrm{L}$ should be a trigger for blood transfusion in mechanically ventilated patients undergoing weaning from mechanical ventilation, but rather that it was an independent predictor for re-intubation.

Muscle weakness was one of the independent predictors for re-intubation in our study. The incidence of ICU-acquired weakness ranges from 25 to $50 \%$, depending on the patient population and measures used for diagnosis. ${ }^{22,44,45}$ Multiple predisposing factors can potentiate ICU-acquired weakness in critically ill patients, such as inflammation, infection, consequence of drug effects, immobilization, and malnutrition. ${ }^{46}$ ICU-acquired weakness was associated with prolonged weaning from mechanical ventilation ${ }^{24}$ and weaning failure. ${ }^{22}$ Weakness in respiratory muscles, as indicated by low maximal inspiratory and expiratory pressure or diaphragmatic dysfunction on ultrasonography, is associated with delayed successful extubation as well as weaning failure. ${ }^{25,26}$

The MRC sum score ${ }^{33}$ has been used to comprehensively assess muscle strength ${ }^{47,48}$ as well as to predict morbidity and mortality in critically ill subjects. ${ }^{45}$ In our study, we used the muscle strength assessed by bedside nurses, and we validated this easily applicable scale with the MRC sum score in our cohort and found a fair agreement $(46.0 \%$ agreement and 0.25 Cohen kappa coefficient). Nevertheless, we did not test for the inter-observer reliability for the muscle strength scale assessed by the bedside nurses. Therefore, we could not completely exclude observer bias. De- 
spite this, this scale has been implemented in our units for $>10 \mathrm{y}$, and all nurses in our units are well trained and familiar with this task as part of their daily routine. The MRC sum score, on the other hand, might have some limitations when performed in critically ill patients, polytrauma patients, or those with altered mental status. ${ }^{45,49} \mathrm{In}$ addition, the MRC sum score cannot be applied simply in daily practice, since the dedicated clinical exam is timeconsuming and requires an expert level of experience. ${ }^{45,49,50}$ The interesting point is that muscle weakness is difficult to reliably quantify: Small differences in the clinical testing procedure lead to meaningful differences in results. Moreover, when talking about a weak patient, health-care providers of different professions may not always have the same clinical picture in mind and draw different conclusions about what to do about their patient's weakness based on nosological misunderstandings. Interestingly, our data indicated that nursing assessment of muscle weakness, which could be performed easily and as an alternative to the MRC sum score, predicted the success of tracheal extubation.

Nowadays, NIV is increasingly used to facilitate early extubation as well as to prevent and manage failed extubation. ${ }^{51,52}$ In our study, the rate of NIV used after extubation was $12 \%$, and of these, $29 \%$ required re-intubation. Our study demonstrated that subjects who required reintubation following a failed NIV attempt had a higher rate of morbidity and mortality than those who did not require re-intubation. One important concern is that the clinicians should have some experience in using NIV, especially when used for management of extubation failure. The patient's respiratory status should be closely monitored, and, if required, re-intubation should not be delayed.

As demonstrated in this present study and others, ${ }^{5,9,13,14,16-18,20}$ extubation failure and re-intubation is strongly associated with increased morbidity and mortality. On the other hand, delayed extubation is associated with worse outcomes, including pneumonia, LOS in ICU and in hospital, and mortality. ${ }^{53}$ It is therefore important not to delay extubation in patients who meet validated criteria of extubation readiness, such as a successful completion of a spontaneous breathing trial. We strongly recommend clinicians to weigh risks versus benefits between delayed extubation and premature extubation and subsequent re-intubation. Our prediction scores for re-intubation, which incorporated parameters that were assessed daily in our subjects, should aid clinicians in identifying those patients with a high risk of extubation failure and in preparing any measures or interventions toward prevention, or treatment if it occurs.

Our study had several limitations. It was an observational study in surgical ICUs of a single large academic medical center. It is unclear whether the results are applicable to different settings, such as a medical ICU. Unlike medical ICU patients, surgical ICU patients usually require a shorter duration of mechanical ventilation support. It was therefore the purpose of the present study to determine the risk factors for re-intubation in the surgical ICU population. Although we included many patient and treatment factors in our analysis, our final model consisted of only 3 factors that explain up to $27 \%$ of re-intubations. There might be significant factors that influence re-intubation but have not been included in our model. The relatively low incidence of re-intubation (8.5\%) in our study may result in an inadequate power for our prediction scores, and we did not validate in an external cohort. The muscle strength, which was included in our prediction scores, was considered as a subjective test. Nevertheless, unlike the MRC sum score, the muscle strength assessment by bedside nurses can be easily performed in our daily routine care. We included all tracheally intubated and mechanically ventilated subjects who proceeded to extubation regardless of the weaning time (eg, simple, difficult, and prolonged weaning). If we had included only patients with difficult and prolonged weaning and complicated postoperative patients, the results might have been different. Finally, at the time of the study performed, high flow nasal oxygen had not been implemented in the protocol following extubation. High flow nasal oxygen has been shown to prevent re-intubation in several patient populations, including cardiac surgical and medical patients. ${ }^{54,55}$ This might also hold true for a general surgical patient population.

\section{Conclusions}

We identified high BUN, low hemoglobin level, and muscle weakness as independent risk factors for re-intubation in surgical ICU subjects. We also provided simple prediction scores for re-intubation, which incorporated parameters that are routinely assessed in ICU patients. The presence of these risk factors can potentially aid clinicians in the decision process around extubation.

\section{REFERENCES}

1. Bittner EA, Schmidt UH. Tracheal reintubation: caused by "too much of a good thing"? Respir Care 2012;57(10):1687-1691.

2. Thille AW, Richard JC, Brochard L. The decision to extubate in the intensive care unit. Am J Respir Crit Care Med 2013;187(12):12941302.

3. MacIntyre NR, Cook DJ, Ely EW Jr, Epstein SK, Fink JB, Heffner $\mathrm{JE}$, et al. Evidence-based guidelines for weaning and discontinuing ventilatory support: a collective task force facilitated by the American College of Chest Physicians; the American Association for Respir Care; and the American College of Critical Care Medicine. Chest 2001;120(6 Suppl):375S-395S.

4. Boles JM, Bion J, Connors A, Herridge M, Marsh B, Melot C, et al. Weaning from mechanical ventilation. Eur Respir J 2007;29(5): 10331056. 


\section{Predictors of Re-Intubation In the Surgical ICU}

5. Epstein SK, Ciubotaru RL, Wong JB. Effect of failed extubation on the outcome of mechanical ventilation. Chest 1997;112(1):186-192.

6. Namen AM, Ely EW, Tatter SB, Case LD, Lucia MA, Smith A, et al. Predictors of successful extubation in neurosurgical patients. Am J Respir Crit Care Med 2001;163(3 Pt 1):658-664.

7. Khamiees M, Raju P, DeGirolamo A, Amoateng-Adjepong Y, Manthous CA. Predictors of extubation outcome in patients who have successfully completed a spontaneous breathing trial. Chest 2001; 120(4):1262-1270.

8. Salam A, Tilluckdharry L, Amoateng-Adjepong Y, Manthous CA. Neurologic status, cough, secretions and extubation outcomes. Intensive Care Med 2004;30(7):1334-1339.

9. Seymour CW, Martinez A, Christie JD, Fuchs BD. The outcome of extubation failure in a community hospital intensive care unit: a cohort study. Crit Care 2004;8(5):R322-R327.

10. Mokhlesi B, Tulaimat A, Gluckman TJ, Wang Y, Evans AT, Corbridge TC. Predicting extubation failure after successful completion of a spontaneous breathing trial. Respir Care 2007;52(12):1710-1717.

11. Navalesi P, Frigerio P, Moretti MP, Sommariva M, Vesconi S, Baiardi P, Levati A. Rate of reintubation in mechanically ventilated neurosurgical and neurologic patients: evaluation of a systematic approach to weaning and extubation. Crit Care Med 2008;36(11): 2986-2992.

12. Su WL, Chen YH, Chen CW, Yang SH, Su CL, Perng WC, et al. Involuntary cough strength and extubation outcomes for patients in an ICU. Chest 2010;137(4):777-782.

13. Frutos-Vivar F, Esteban A, Apezteguia C, González M, Arabi Y, Restrepo MI, et al. Outcome of reintubated patients after scheduled extubation. J Crit Care 2011;26(5):502-509.

14. Thille AW, Harrois A, Schortgen F, Brun-Buisson C, Brochard L. Outcomes of extubation failure in medical intensive care unit patients. Crit Care Med 2011;39(12):2612-2618.

15. Brown CV, Daigle JB, Foulkrod KH, Brouillette B, Clark A, Czysz $\mathrm{C}$, et al. Risk factors associated with early reintubation in trauma patients: a prospective observational study. J Trauma 2011;71(1):3741; discussion 41-32.

16. Savi A, Teixeira C, Silva JM, Borges LG, Pereira PA, Pinto KB, et al. Weaning predictors do not predict extubation failure in simpleto-wean patients. J Crit Care 2012;27(2):221.e1-8.

17. Menon N, Joffe AM, Deem S, Yanez ND, Grabinsky A, Dagal AH, et al. Occurrence and complications of tracheal reintubation in critically ill adults. Respir Care 2012;57(10):1555-1563.

18. Saugel B, Rakette P, Hapfelmeier A, Schultheiss C, Phillip V, Thies $\mathrm{P}$, et al. Prediction of extubation failure in medical intensive care unit patients. J Crit Care 2012;27(6):571-577.

19. Miu T, Joffe AM, Yanez ND, Khandelwal N, Dagal AH, Deem S, Treggiari MM. Predictors of reintubation in critically ill patients. Respir Care 2014;59(2):178-185.

20. Epstein SK, Ciubotaru RL. Independent effects of etiology of failure and time to reintubation on outcome for patients failing extubation. Am J Respir Crit Care Med 1998;158(2):489-493.

21. Torres A, Gatell JM, Aznar E, el-Ebiary M, Puig de la Bellacasa J, Gonzalez J, et al. Re-intubation increases the risk of nosocomial pneumonia in patients needing mechanical ventilation. Am J Respir Crit Care Med 1995;152(1):137-141.

22. Garnacho-Montero J, Amaya-Villar R, García-Garmendía JL, Madrazo-Osuna J, Ortiz-Leyba C. Effect of critical illness polyneuropathy on the withdrawal from mechanical ventilation and the length of stay in septic patients. Crit Care Med 2005;33(2):349-354.

23. Mirzakhani H, Williams JN, Mello J, Joseph S, Meyer MJ, Waak K, et al. Muscle weakness predicts pharyngeal dysfunction and symptomatic aspiration in long-term ventilated patients. Anesthesiology 2013;119(2):389-397.
24. De Jonghe B, Bastuji-Garin S, Sharshar T, Outin H, Brochard L. Does ICU-acquired paresis lengthen weaning from mechanical ventilation? Intensive Care Med 2004;30(6):1117-1121.

25. De Jonghe B, Bastuji-Garin S, Durand MC, Malissin I, Rodrigues P, Cerf C, et al. Respiratory weakness is associated with limb weakness and delayed weaning in critical illness. Crit Care Med 2007;35(9): 2007-2015.

26. Kim WY, Suh HJ, Hong SB, Koh Y, Lim CM. Diaphragm dysfunction assessed by ultrasonography: influence on weaning from mechanical ventilation. Crit Care Med 2011;39(12):2627-2630.

27. Walcher A, Faubel S, Keniston A, Dennen P. In critically ill patients requiring CRRT, AKI is associated with increased respiratory failure and death versus ESRD. Ren Fail 2011;33(10):935-942.

28. Vieira JM, Jr., Castro I, Curvello-Neto A, Demarzo S, Caruso P, Pastore L Jr, et al. Effect of acute kidney injury on weaning from mechanical ventilation in critically ill patients. Crit Care Med 2007; 35(1):184-191.

29. Wu YK, Kao KC, Hsu KH, Hsieh MJ, Tsai YH. Predictors of successful weaning from prolonged mechanical ventilation in Taiwan. Respir Med 2009;103(8):1189-1195.

30. Pan SW, Kao HK, Lien TC, Chen YW, Kou YR, Wang JH. Acute kidney injury on ventilator initiation day independently predicts prolonged mechanical ventilation in intensive care unit patients. J Crit Care 2011;26(6):586-592.

31. Brueckmann B, Villa-Uribe JL, Bateman BT, Grosse-Sundrup M, Hess DR, Schlett CL, Eikermann M. Development and validation of a score for prediction of postoperative respiratory complications. Anesthesiology 2013;118(6):1276-1285.

32. Bellomo R, Ronco C, Kellum JA, Mehta RL, Palevsky P. Acute renal failure: definition, outcome measures, animal models, fluid therapy and information technology needs: the Second International Consensus Conference of the Acute Dialysis Quality Initiative (ADQI) Group. Crit Care 2004;8(4):R204-R212.

33. Kleyweg RP, van der Meché FG, Schmitz PI. Interobserver agreement in the assessment of muscle strength and functional abilities in Guillain-Barre syndrome. Muscle Nerve 1991;14(11):1103-1109.

34. Aronson D, Mittleman MA, Burger AJ. Elevated blood urea nitrogen level as a predictor of mortality in patients admitted for decompensated heart failure. Am J Med 2004;116(7):466-473.

35. Beier K, Eppanapally S, Bazick HS, Chang D, Mahadevappa K, Gibbons FK, Christopher KB. Elevation of blood urea nitrogen is predictive of long-term mortality in critically ill patients independent of "normal" creatinine. Crit Care Med 2011;39(2):305-313.

36. Hayden SJ, Albert TJ, Watkins TR, Swenson ER. Anemia in critical illness: insights into etiology, consequences, and management. Am J Respir Crit Care Med 2012;185(10):1049-1057.

37. Prakash D. Anemia in the ICU: anemia of chronic disease versus anemia of acute illness. Crit Care Clin 2012;28(3):333-343, v.

38. Retter A, Wyncoll D, Pearse R, Carson D, McKechnie S, Stanworth S, et al. Guidelines on the management of anaemia and red cell transfusion in adult critically ill patients. Br J Haematol 2013;160(4):445-464.

39. Lai YC, Ruan SY, Huang CT, Kuo PH, Yu CJ. Hemoglobin levels and weaning outcome of mechanical ventilation in difficult-to-wean patients: a retrospective cohort study. PLoS One 2013;8(8):e73743.

40. Hajjar LA, Vincent JL, Galas FR, Nakamura RE, Silva CM, Santos $\mathrm{MH}$, et al. Transfusion requirements after cardiac surgery: the TRACS randomized controlled trial. JAMA 2010;304(14):1559-1567.

41. Carson JL, Terrin ML, Noveck H, Sanders DW, Chaitman BR, Rhoads GG, et al. Liberal or restrictive transfusion in high-risk patients after hip surgery. N Engl J Med 2011;365(26):2453-2462.

42. Villanueva C, Colomo A, Bosch A, Concepción M, Hernandez-Gea $\mathrm{V}$, Aracil C, et al. Transfusion strategies for acute upper gastrointestinal bleeding. N Engl J Med 2013;368(1):11-21. 


\section{Predictors of Re-Intubation In the Surgical ICU}

43. Holst LB, Haase N, Wetterslev J, Wernerman J, Guttormsen AB, Karlsson S, et al. Lower versus higher hemoglobin threshold for transfusion in septic shock. N Engl J Med 2014;371(15):1381-1391.

44. De Jonghe B, Sharshar T, Lefaucheur JP, Authier FJ, Durand-Zaleski I, Boussarsar M, et al. Paresis acquired in the intensive care unit: a prospective multicenter study. JAMA 2002;288(22):2859-2867.

45. Lee JJ, Waak K, Grosse-Sundrup M, Xue F, Lee J, Chipman D, et al. Global muscle strength but not grip strength predicts mortality and length of stay in a general population in a surgical intensive care unit. Phys Ther 2012;92(12):1546-1555.

46. Eikermann M, Latronico N. What is new in prevention of muscle weakness in critically ill patients? Intensive Care Med 2013;39(12): 2200-2203.

47. Fan E, Ciesla ND, Truong AD, Bhoopathi V, Zeger SL, Needham DM. Inter-rater reliability of manual muscle strength testing in ICU survivors and simulated patients. Intensive Care Med 2010;36(6): 1038-1043.

48. Hermans G, Clerckx B, Vanhullebusch T, Segers J, Vanpee G, Robbeets $\mathrm{C}$, et al. Interobserver agreement of Medical Research Council sum-score and handgrip strength in the intensive care unit. Muscle Nerve 2012;45(1):18-25.

49. Hough CL, Lieu BK, Caldwell ES. Manual muscle strength testing of critically ill patients: feasibility and interobserver agreement. Crit Care 2011;15(1):R43.
50. Waak K, Zaremba S, Eikermann M. Muscle strength measurement in the intensive care unit: not everything that can be counted counts. J Crit Care 2013;28(1):96-98.

51. Glossop AJ, Shepherd N, Bryden DC, Mills GH. Non-invasive ventilation for weaning, avoiding reintubation after extubation and in the postoperative period: a meta-analysis. Br J Anaesth 2012;109(3): 305-314.

52. Burns KE, Meade MO, Premji A, Adhikari NK. Noninvasive positive-pressure ventilation as a weaning strategy for intubated adults with respiratory failure. Cochrane Database Syst Rev 2013;(12): CD004127.

53. Coplin WM, Pierson DJ, Cooley KD, Newell DW, Rubenfeld GD. Implications of extubation delay in brain-injured patients meeting standard weaning criteria. Am J Respir Crit Care Med 2000;161(5): 1530-1536.

54. Frat JP, Thille AW, Mercat A, Girault C, Ragot S, Perbet S, et al. High-flow oxygen through nasal cannula in acute hypoxemic respiratory failure. N Engl J Med 2015;372(23):2185-2196.

55. Stéphan F, Barrucand B, Petit P, Rézaiguia-Delclaux S, Médard A, Delannoy B, et al. High-flow nasal oxygen vs noninvasive positive airway pressure in hypoxemic patients after cardiothoracic surgery: a randomized clinical trial. JAMA 2015;313(23): 2331-2339. 